Article

\title{
Development of BIM Execution Plan for BIM Model Management during the Pre-Operation Phase: A Case Study
}

\author{
Yu-Cheng Lin *, Yen-Pei Chen, Wan-Ting Huang and Chia-Chun Hong \\ Department of Civil Engineering, National Taipei University of Technology (Taipei Tech), No.1, Sec.3, \\ Chung-Hsiao East Road, Taipei 10608, Taiwan; gbass1988@hotmail.com (Y.-P.C.); ewth918@gmail.com (W.-T.H.); \\ jean800308@gmail.com (C.-C.H.) \\ * Correspondence: yclinntut@gmail.com; Tel.: +886-2-2771-2171 (ext. 2673); Fax: +886-2-8773-0102 \\ Academic Editor: Wolfgang Kastner \\ Received: 2 September 2015; Accepted: 4 February 2016; Published: 17 February 2016
}

\begin{abstract}
Building information modeling (BIM) technologies use precise geometry and relevant data to enhance and improve the maintenance performance of facilities integrated with 3D object-oriented computer aided design (CAD). Although most owners agree on the potential benefits of integrating BIM technologies with facility management (FM), they must overcome many problems to plan and develop effective BIM execution plans for FM implementation. This study proposes and develops a BIM execution plan for BIM model management for FM during the pre-operation phase. Through the application of the proposed BIM execution plan, BIM can be effectively implemented during the operation and maintenance phases. In order to verify the proposed methodology and demonstrate its effectiveness in practice, the BIM execution plan is then applied in a selected case study of a building project in Taiwan. The combined results demonstrate that the proposed BIM execution plan is an effective approach for operation and maintenance management. The advantage of the proposed BIM execution plan lies not only in improving the efficiency of maintenance management work when integrated with BIM technologies, but also in maximizing the value and benefits of BIM to support maintenance management. Finally, limitations, difficulties, and suggestions are summarized for further development of the BIM execution plan for BIM model management during the pre-operation phase.
\end{abstract}

Keywords: BIM; building information modeling; maintenance management; facility management

\section{Introduction}

Building information modeling (BIM) technologies use precise geometry and relevant data to enhance and improve the maintenance service of facilities through the 3D object-oriented CAD. Although most owners agree on the potential benefits of BIM technologies integrated with facility management (FM), there are many problems for the owners to plan and develop effective BIM execution plans for FM implementation. This study proposes and develops a BIM execution plan for FM, especially during the operation and maintenance phase. With the assistance of BIM technology, many limitations regarding 2D drawings can be improved effectively because of the $3 \mathrm{D}$ visual illustration capability. Although there are many advantages in using BIM for FM, there are many difficulties associated with the planning and application of BIM for FM during the pre-operation phase.

Although many studies have focused on the application of BIM technology during the operation phase, little research has considered the development of a BIM execution plan for owners during the pre-operation phase. In Taiwan, most owners receive as-built BIM models from the general contractor during project closeout phase. Without suitable plans and approaches, it is difficult for owners to 
prepare and implement BIM technology for FM. Consequently, there can be significant gaps and difficulties in real applications of BIM in FM. According to survey findings regarding BIM-FM-ready work in Taiwan [1], the primary problems regarding real BIM implementation for FM for owners are as follows: (1) there is no suitable BIM plan for BIM model management to guide BIM execution during the pre-operation phase; (2) there is no approach to the confirm the accuracy of the final as-built BIM models when the general contractors deliver the BIM model to the owner; and (3) there is no suitable management mechanism to implement BIM model management. Few suitably simple approaches exist that can assist owners in developing BIM-FM execution plans and identifying their requirements during the pre-operation phase.

In order to improve the above problems, it is necessary for owners to develop a BIM execution plan during the pre-operation phase. With the assistance of the proposed BIM execution plan, the implementation of a BIM can be effective during the operation phase. The primary objectives of this study include: (1) identifying for owners the primary problems regarding BIM implementation for FM; (2) developing for owners a BIM execution plan during the pre-operation phase; and (3) exploring limitations, addressing problems, and providing suggestions based on the implementation of the pilot case study. Through the application of the proposed BIM execution plan, BIM can be effectively implemented during the operation phase. Furthermore, the proposed BIM execution plan is then applied in a selected case study of a building project in Taiwan to verify the proposed approach and demonstrate its effectiveness in practice. Finally, limitations, challenges, and suggestions are summarized for further development of the BIM execution plan in practice.

\section{Related Research Studies}

The precise geometry and relevant data provided by BIM digitally to assist the design, procurement, fabrication, and construction activities through the use of 3D object-oriented CAD [2]. The potential benefits of BIM for facility management (FM) have been acknowledged by the AEC industry [3]. William East et al. [4] proposed the facility management (FM) handover model view definition (MVD) to replace current construction handover document requirements. Becerik-Gerber et al. [5] explored how BIM can be a beneficial platform for supplementing FM practices based on an online survey and face-to-face interviews. Wang et al. [6] illustrated how BIM would beneficially improve the preference of FM work during the design phase. Bosch et al. [7] investigated information management during the operations stage from the viewpoint of owners and determined the added value of BIM within this growing field of construction. Kassem et al. [8] provided a real-life case study of BIM in FM and explored empirical evidence of both the value and challenges of BIM in FM applications. Arayici et al. [9] explained how BIM could contribute to and improve the FM profession service.

The BIM approach, which is used to illustrate facility-related information in a digital format, provides effective updates of FM information in a 3D CAD environment. There are many practical studies on the use of BIM in the operation phase. Motamedi et al. [10] utilized characteristic of BIM visualization to assist FM work with visualizations for utilizing problem solving effectively. Kang and Hong [11] proposed a software architecture for the effective integration of BIM into a geographic information system (GIS)-based FM system. Lin et al. [12] proposed a mobile automated BIM-based facility management (BIMFM) system integrated with 2D barcode for FM staff in the operation phase. Motawa and Almarshad [13] developed an integrated system to capture, retrieve, and manage information/knowledge for asset management and building maintenance. Love et al. [14] proposed a systems information model integrated with BIM for asset managers and staff to make more informed and quicker decisions about maintenance.

There are many BIM guides with implementation strategies to outline the various possible deliverables, processes and personnel using BIM in the design phase, the construction phase, or the operation phase based on the different roles and responsibilities of project members [15]. 
Messner et al. [16] developed a BIM guide to aid facility owners as they develop strategic, implementation, and procurement plans for integrating BIM in their organizations.

Although there are many studies that focus on the application of BIM technology during the operation phase, there is little research that focuses on assisting the owners in developing BIM execution plans during the pre-operation phase. Without the suitable plans and approaches, it is hard for the owners to know how to plan and implement the BIM technology for facility management. In order to improve the above problems, it is necessary for the owners to develop BIM execution plans during the pre-operation phase. With the assistance of the proposed BIM execution plans, the implementation of BIM can be effective during the operation phase.

\section{Proposed Approach}

The preparation of BIM work at the early stage of the operation phase is very important for BIM-FM implementation. The involvement of the facility management team at this early stage can be helpful for BIM-FM implementation purposes. However, in reality, the facility management team may not have been established in its early stages. Thus, the initial development of a BIM execution plan of operation and maintenance management could solve this problem. The initial development of a BIM execution plan presents a structured approach to effectively design the integration of a BIM for FM. Many plans and processes need to be developed for BIM-FM implementation at the early stages of the operation phase to subsequently implement the BIM-FM successfully. Figure 1 shows the process of the as-built BIM models delivered to the owner to be updated for as-built BIM models for FM. Before the start of BIM implementation for BIM-FM work during the pre-operation phase, all as-built BIM models should be confirmed and updated for FM. Those tasks include developing a related plan to confirm the accuracy of as-built BIM models for FM and setting up related processes for the implementation of BIM-FM work during the operation phase.

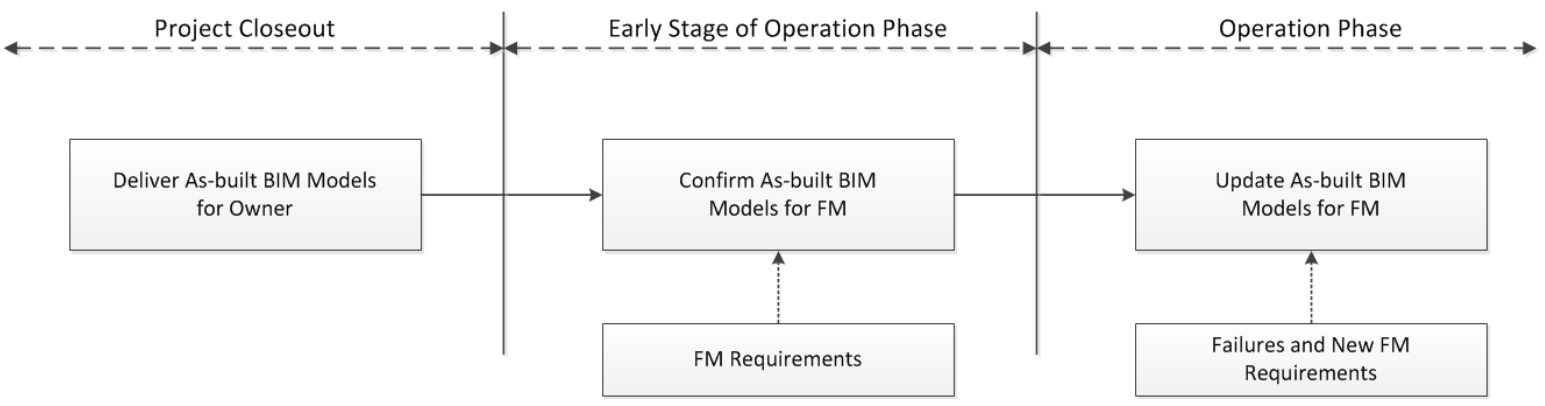

Figure 1. The process of the as-built Building Information Modeling (BIM) models delivered to update as-built BIM models for facility management (FM).

The implementation process will vary from one organization to another depending on its goals and objectives, the size of the organization, available resources and time, financial support, and experience with BIM. Therefore, one of the major objectives of the study is to help owners to determine a defined approach to develop a BIM execution plan in order to avoid the risk of cost overrun and misdirected time and resources. There are seven BIM execution plan core elements proposed in the study that must be considered based on the interview with industry experts (Figure 2). The seven proposed BIM execution plan core elements are as follows: 


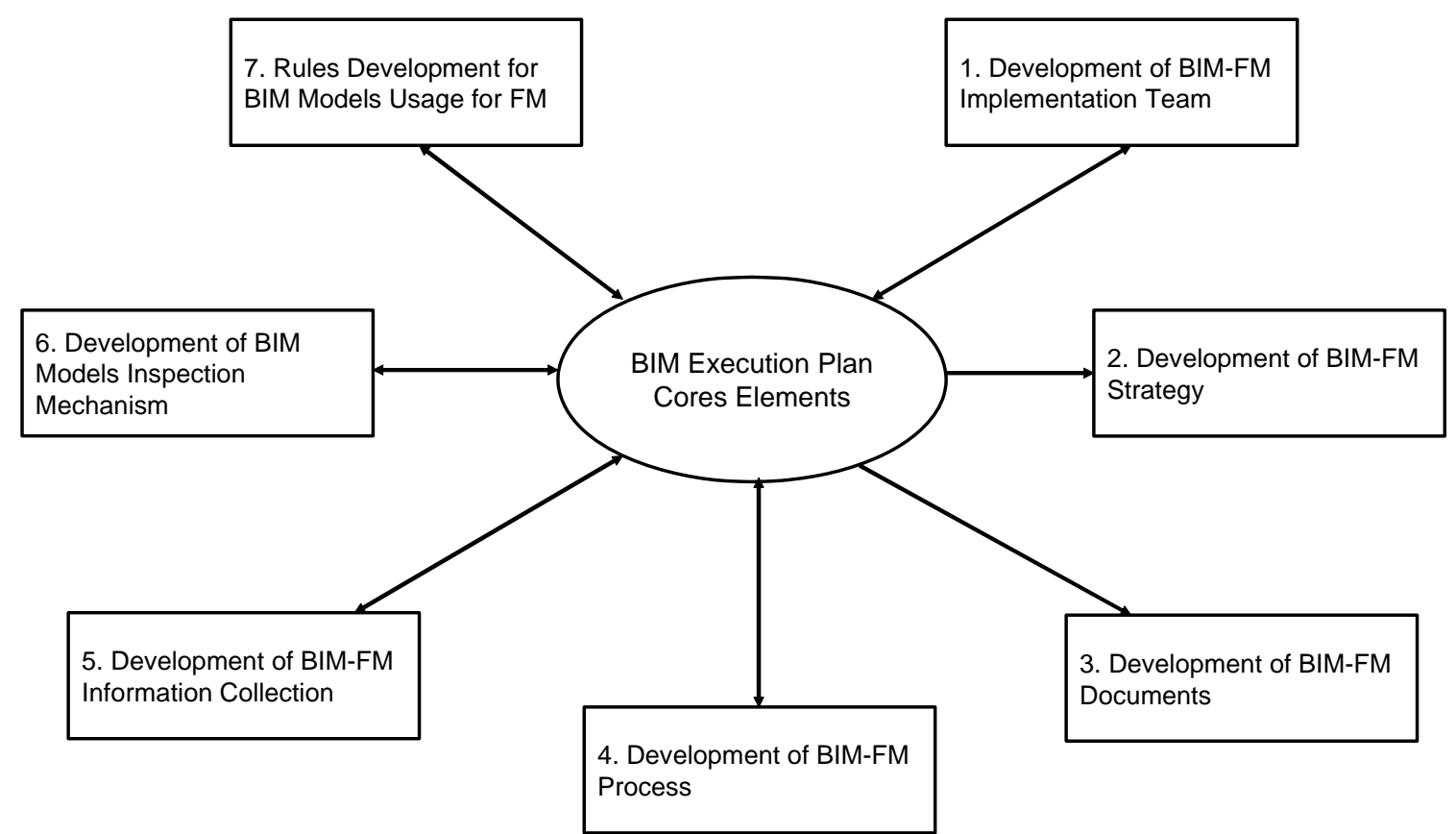

Figure 2. Proposed seven BIM execution plan core elements for BIM-FM purpose.

\subsection{Development of BIM-FM Implementation Team}

The establishment of a proper team and personnel for BIM-FM implementation is one of the most critical factors to successful implementation and integration of BIM. The BIM manager(s) and a few key members of the BIM-FM implementation committee should become members of the BIM-FM team. It is very important for an owner to establish the roles and responsibilities of each participant in the BIM implementation process for FM. With a BIM Implementation Team established, the roles and responsibilities of each member of the team should be agreed upon and documented. This includes requirements and deliverables for each individual on the team.

In order to enhance the performance of BIM execution for operation and maintenance management, the study proposes seven major roles for BIM FM implementation. Based on expert's interview, these roles include FM manager, owner, BIM engineer, Information Technology (IT) Engineer, FM staff, Facility Suppliers, and users. More detailed information regarding each role is given below (Table 1).

Table 1. The detailed required roles for BIM model usage for FM.

\begin{tabular}{ll}
\hline \multicolumn{1}{c}{ Project Participants } & \multicolumn{1}{c}{ Definition } \\
\hline FM Manager & $\begin{array}{l}\text { The person who manages facility services, ensures that an organization meets the most } \\
\text { suitable objectives, and determines relevant BIM FM activities. }\end{array}$ \\
\hline Owner & The person who decides major decisions and requirements for the application of BIM in FM. \\
\hline BIM Engineer & $\begin{array}{l}\text { The person who helps the owners to create the initial BIM-related implementation plan for } \\
\text { the BIM use for FM; and to develop, revise, update related BIM model during the } \\
\text { pre-operation phase. }\end{array}$ \\
\hline IT Engineer & $\begin{array}{l}\text { The person who plans and develops the detailed plan for integrated BIM-FM system during } \\
\text { the pre-operation phase. }\end{array}$ \\
\hline FM Staff & $\begin{array}{l}\text { The person who handles equipment repair work in the FM department and reports the status, } \\
\text { problems, and results of maintenance to related FM participants for improving FM } \\
\text { management. }\end{array}$ \\
\hline Facility Suppliers & $\begin{array}{l}\text { The person who supports facilities by assisting with their setup and repairs when needed. } \\
\text { Users }\end{array}$ \\
\hline
\end{tabular}




\subsection{Development of BIM-FM Strategy}

A suitable strategy for BIM implementation for FM provides the BIM-FM team a plan to operate the BIM-FM successfully. It is necessary to define the goals and objectives for implementing BIM for FM. In order to develop a BIM-FM strategy, all FM participants, including top management need to meet and identify the major requirements and objectives of BIM-FM implementation. Furthermore, those identified strategies should be documented for future sharing and revision. Each BIM-FM strategy will be different in terms of its requirements and objectives for BIM implementation for FM. Those strategies include process checking, related processes of BIM model development, and a framework for maintenance management. Therefore, all FM participants (including top management) should establish the BIM-FM goals for future BIM implementation.

\subsection{Development of BIM-FM Documents}

It is necessary to develop suitable documents and tables for BIM implementation for FM integral to strategy identification and documentation. It is very important to create the requirements for these documents and tables for which the BIM will be implemented. The purpose of these documents and tables are designed for detail description and management for BIM implementation for FM. These documents and tables assist with BIM model inspection work and include basic information/date of the BIM model elements of the facility/equipment; the facility supporter's information; and, the operation manual that is externally linked with the BIM model element. The initial documentation includes generating, processing, communicating, executing, and managing information concerning the FM tasks related to the major requirements and objectives of BIM-FM implementation. Furthermore, those proposed documents and tables should be documented for future sharing and revision. In this core element, all FM participants should provide feedback on the problems they face and suggest better usage of documents and tables for BIM implementation.

\subsection{Development of BIM-FM Process}

This core element describes the means to accomplish BIM usage by documenting the current processes, designing new BIM processes, and developing transition processes. Usually, FM operations include multiple operation tasks and responsibilities. Knowledge of these existing processes is essential to creating and developing new processes with the assistance of BIM technology. It is these tasks and responsibilities that should be clearly documented. Checklists and milestones must be developed for BIM management for FM.

\subsection{Development of BIM-FM Information Collection}

Authorized staff needs to identify the information to be displayed and integrated with the BIM models. Furthermore, they need to define the information needs of the organization, including model element breakdowns, levels of development, and facility data (such as facility profile, model parameters, and external links information). These items include the people responsible for implementing the phases, checkpoints throughout the time frame, and links between drivers that support their mutual advancement. The development of a detailed roadmap involves FM-related work sessions or workshops with various members of the BIM-FM team. An analysis of project status, the desired level of maturity, and the gaps to be bridged should be identified. The sequence in which the BIM Planning Elements should be identified and developed based on the specific BIM goals and objectives.

\subsection{Development of BIM Models Inspection Mechanism}

Owners may use and revise the final as-built BIM models delivered from the general contractor in the pre-operation phase. The proposed flowchart is developed for the BIM models inspection mechanism. When the general contractor delivers the final as-built BIM models to the owner, the 
owner needs to inspect the accuracy of the final BIM models for FM usage based on the contract. Furthermore, the proposed process is developed so that the owner can inspect the accuracy of the final BIM models before the BIM is applied to operation and maintenance management. The major content of the proposed process includes: inspecting BIM element information; confirming the positions within the BIM models compared with the actual facility/equipment positions; and determining if certain basic information of the BIM models must be updated or revised. Staff authorized by the owner may carry tablets that can access the BIM model and go to the facility/equipment position directly for BIM model inspection work. Finally, the authorized staff will identify the problems, make statements and take photos of the problems discovered, and submit the problems to BIM engineers for a solution.

During the process of BIM model inspection work, a detailed record of new BIM model development, revised BIM models, and deleted BIM models should be recorded and traced completely. The major purpose of the process management is to reduce the potential for errors and misunderstandings in the application of the revised BIM models. Furthermore, it is important to verify the integrity and accuracy of BIM models in order to meet the requirements of the BIM application for operation and maintenance management. In order to fulfill these needs, the study proposes managed documents and tables for BIM model inspection work.

The BIM model inspection work consists of two parts. The first part is to inspect and confirm the basic information of BIM model elements. The main content of this part includes basic information/date of the BIM model elements of the facility/equipment (such as name and information of BIM model element of the facility/equipment). The second part is to confirm the location of facility/equipment and verify the related information compared with real facility/equipment. Any problems and suggestions are recorded and traced in the event of a problem being identified by FM staff or the BIM engineer. Finally, the BIM engineer will revise and modify the BIM models using the proposed managed documents and tables based on the identified problems. Figure 3 shows the process of BIM models inspection mechanism during pre-operation phase.

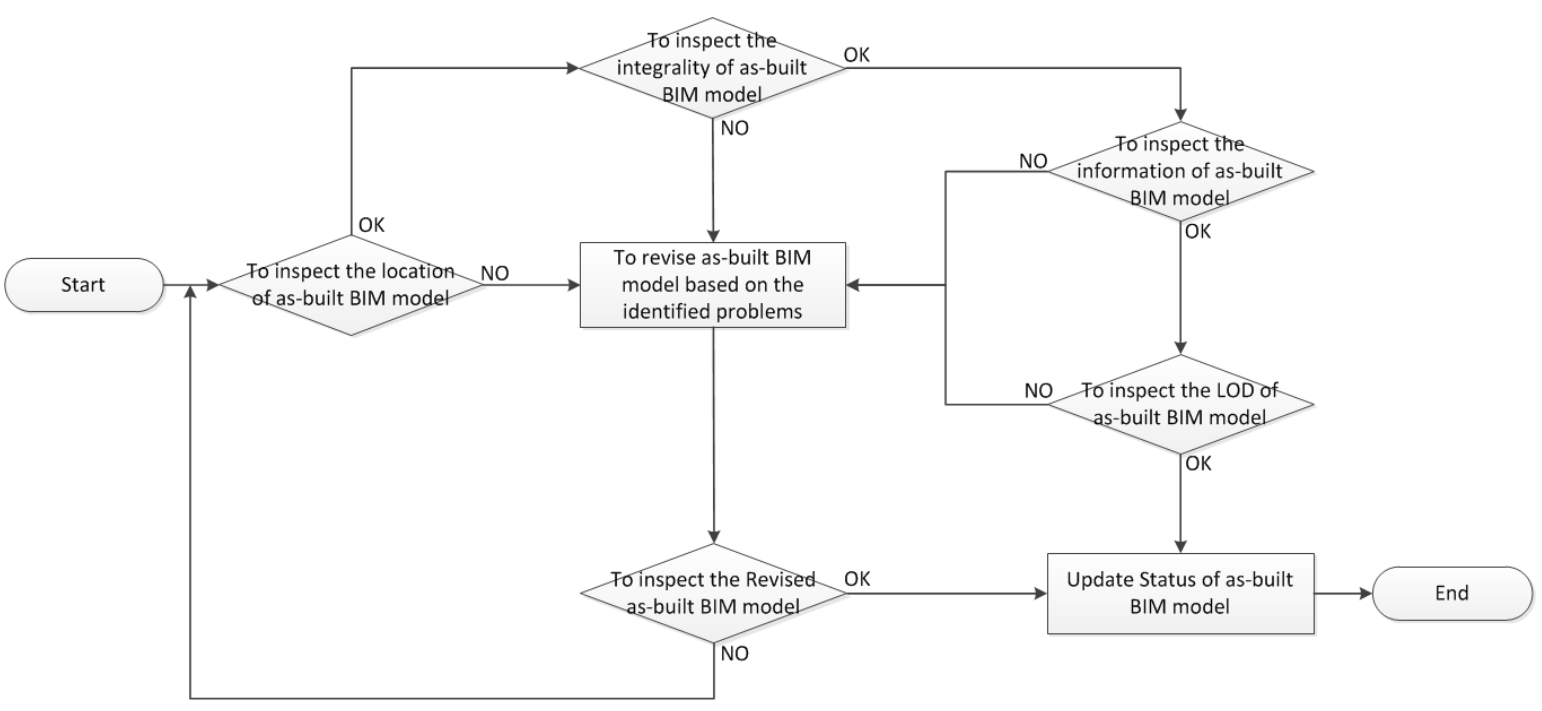

Figure 3. The process of BIM models inspection mechanism during pre-operation phase.

\subsection{Rules Development for BIM Models Usage for FM}

To assist the operation of the maintenance phase using BIM technology, rule development of BIM models usage for FM should be planned initially for effective BIM management purpose. The rule development results of BIM models usage for FM are described in detail in the section below. 


\subsubsection{The Color Plan Development of BIM Models}

The identification and development of the color plan of BIM model for FM is necessary for advanced management. The different color illustrations for facility/equipment classification provide those visual illustrations of BIM models for FM that can be enhanced for effective tracing and management. Furthermore, different management statuses of facility/equipment can be depicted with different colors to reflect the elements of BIM models.3.7.2. The Analysis of Level of Detail (LOD) for BIM Model

The required analysis of Level of Detail (LOD) for BIM model is necessary and important for FM usage. There are six LOD (such as LOD 100, 200, 300, 350, 400, and 500) based on the The American Institute of Architects (AIA) Contract Documents Committee. While most of FM projects conduct up to LOD 500 for BIM models as the FM requirement, it is very important and necessary to develop strategies to identify the required LOD of the BIM model for the different facilities or equipment. Based on the interviews with BIM experts in Taiwan, most agree that not all BIM models require up to LOD 500 as the FM requirement. The major reason given is to balance the smaller file size and the faster modeling work. Therefore, the study proposes the detailed required sheet of BIM model for FM to understand the detailed required information of BIM model for every facility or equipment in the pre-operation phase. The identified information of the proposed detailed required sheet of BIM model includes the basic information (such as the equipment name and purchasing data), geometric information (such as the length and width of the equipment), detailed equipment information (such as equipment supplier information), and related supplementary information (such as user manual). The detailed required sheets of BIM models are completed based on input from the meetings or discussion. All BIM models for FM can then be revised and updated based on the approved detailed required sheets of BIM models. Furthermore, the detailed required sheets of BIM models can be modified and revised based on different purposes. With the assistance of the detailed required sheet of BIM model for FM, the required LOD for BIM model for FM can be solved effectively.

\subsubsection{The Confirmation of Information for BIM Model}

In the study, there are five types of required information regarding each facility/equipment BIM model. They are facility/equipment basic information, facility/equipment geometric information, facility/equipment detailed information, facility/equipment supplementary information, and facility/equipment related maintenance information. In order to understand and confirm the required information for the element of BIM model, the study collects and proposes the detailed required sheet of BIM model for FM for enhancing information entry accuracy integrated with BIM models based on experts' interviews (Table 2). Usually, effective data analysis is the key to success for facility and maintenance management. During the operation, computerized maintenance management systems (CMMS) are essential for gathering and analyzing the related information for FM manager and staff. Increasingly, it is important and necessary to use the integrated BIM technology with the construction operations building information exchange (COBie) to enhance the information communication of their CMMS. Therefore, the integration of COBie with BIM for FM is an important step for information integration for FM. 
Table 2. The detailed required sheet of BIM model for FM.

\begin{tabular}{|c|c|c|c|}
\hline Number:004 & Date: $2015 / 11 / 05$ & \multicolumn{2}{|c|}{ Staff of Fill out the form: Huang** } \\
\hline \multirow{5}{*}{ Profile } & \multirow{5}{*}{ Basic information } & System class & Supply and drainage system \\
\hline & & Equipment name & Bottled-water cooler \\
\hline & & $\begin{array}{l}\text { Developing BIM model of } \\
\text { equipment }\end{array}$ & $\nabla$ \\
\hline & & Appearance description(word) & $\nabla$ \\
\hline & & Appearance example(picture) & $\nabla$ \\
\hline \multirow{18}{*}{ Model parameters } & \multirow{4}{*}{ Geometric information } & Size (Length, Width, Height) & $\nabla$ \\
\hline & & Material & $\nabla$ \\
\hline & & Elevation & $\nabla$ \\
\hline & & $\begin{array}{l}\text { Special detail of model } \\
\text { (word / picture) }\end{array}$ & $\nabla$ \\
\hline & \multirow{14}{*}{$\begin{array}{l}\text { Equipment detail } \\
\text { information }\end{array}$} & Equipment number & $\nabla$ \\
\hline & & Omniclass coding & $\nabla$ \\
\hline & & Brand / Manufacturer & $\nabla$ \\
\hline & & Manufacturing company & $\square$ \\
\hline & & Location (area / floor) & $\nabla$ \\
\hline & & Price & $\nabla$ \\
\hline & & Purchase date & $\nabla$ \\
\hline & & Installation date & $\nabla$ \\
\hline & & Responsible unit / person & $\nabla$ \\
\hline & & Equipment specifications & $\nabla$ \\
\hline & & Equipment type & $\nabla$ \\
\hline & & Equipment functions & $\square$ \\
\hline & & Equipment units & $\square$ \\
\hline & & $\begin{array}{l}\text { Equipment professional } \\
\text { information }\end{array}$ & $\nabla$ \\
\hline \multirow{11}{*}{$\begin{array}{l}\text { External links } \\
\text { information }\end{array}$} & \multirow{7}{*}{$\begin{array}{l}\text { Supplementary } \\
\text { information }\end{array}$} & Warranty & $\nabla$ \\
\hline & & Assembly process & $\square$ \\
\hline & & Operating manual & $\nabla$ \\
\hline & & 2D CAD & $\square$ \\
\hline & & Equipment performance table & $\square$ \\
\hline & & Manufacturer information & $\nabla$ \\
\hline & & Maintenance manual & $\square$ \\
\hline & \multirow{4}{*}{ Maintenance records } & Equipment resume & $\nabla$ \\
\hline & & History maintenance records & $\nabla$ \\
\hline & & Checklist & $\nabla$ \\
\hline & & $\begin{array}{l}\text { Record book of maintenance } \\
\text { staff }\end{array}$ & $\square$ \\
\hline
\end{tabular}

\section{Cast Study and Discussion}

The proposed BIM execution plan was applied to a new building in Taiwan as an initial case study. This study developed a BIM execution plan for BIM-FM implementation based on the requirements for FM use. The general contractor delivered the final as-built BIM model to the owner during the project closeout phase. Senior management of the owner made a decision to collaborate with the 
involved participants to pilot test the proposed BIM execution plan for the building project to gain feedback, including possible problems and results. Participants included the FM manager, FM staff, and the BIM engineer affiliated with the owner. The BIM execution plan was developed after the owner's BIM-FM goals were established. During the process, the proposed BIM execution plan was enforced, revised, and updated based on feedback gained from numerous BIM-FM meetings with the owner. The exact details and characteristics of the project will not be discussed in this paper due to confidentiality reasons. Figure 4 illustrates updated as-built BIM model for FM from as-built BIM model in the case study. The as-built model element lacked bottled water cooler based on the requirements of the contract (left); therefore, the element as-built model needed to be updated (right). Figure 5 shows the updated as-built BIM model and related FM data table of the bottled water cooler used in the case study. Figure 6 shows the use of the detailed required sheet of BIM model for FM used in the case study. Finally, Figure 7 shows the use of the new BIM models inspection process in the case study.
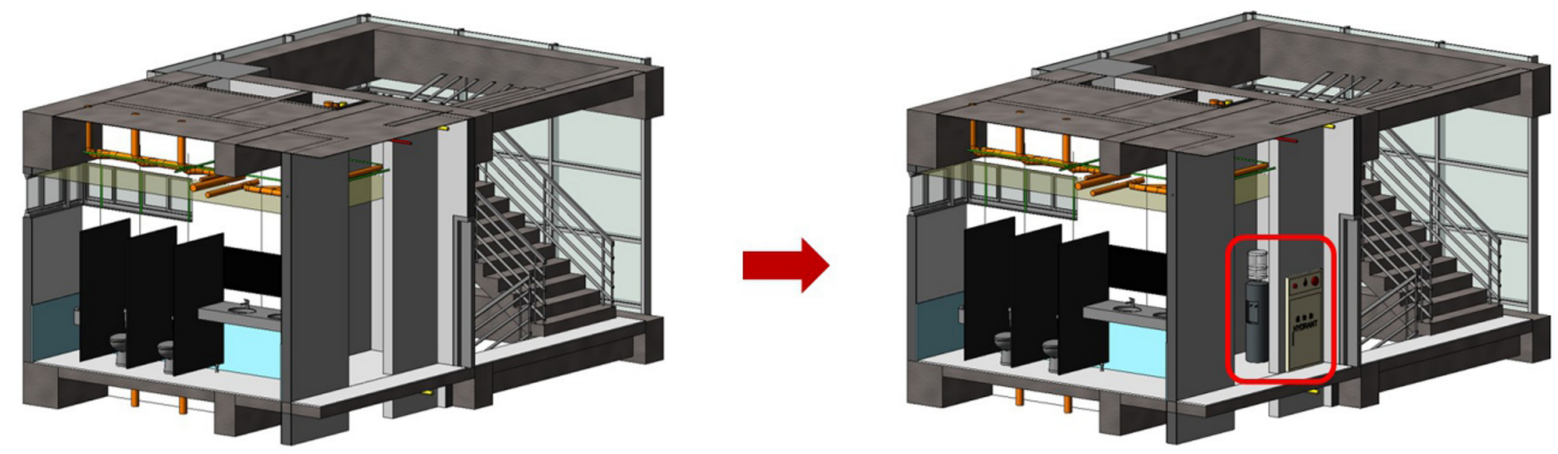

Figure 4. Updated As-Built BIM model for FM in the case study.

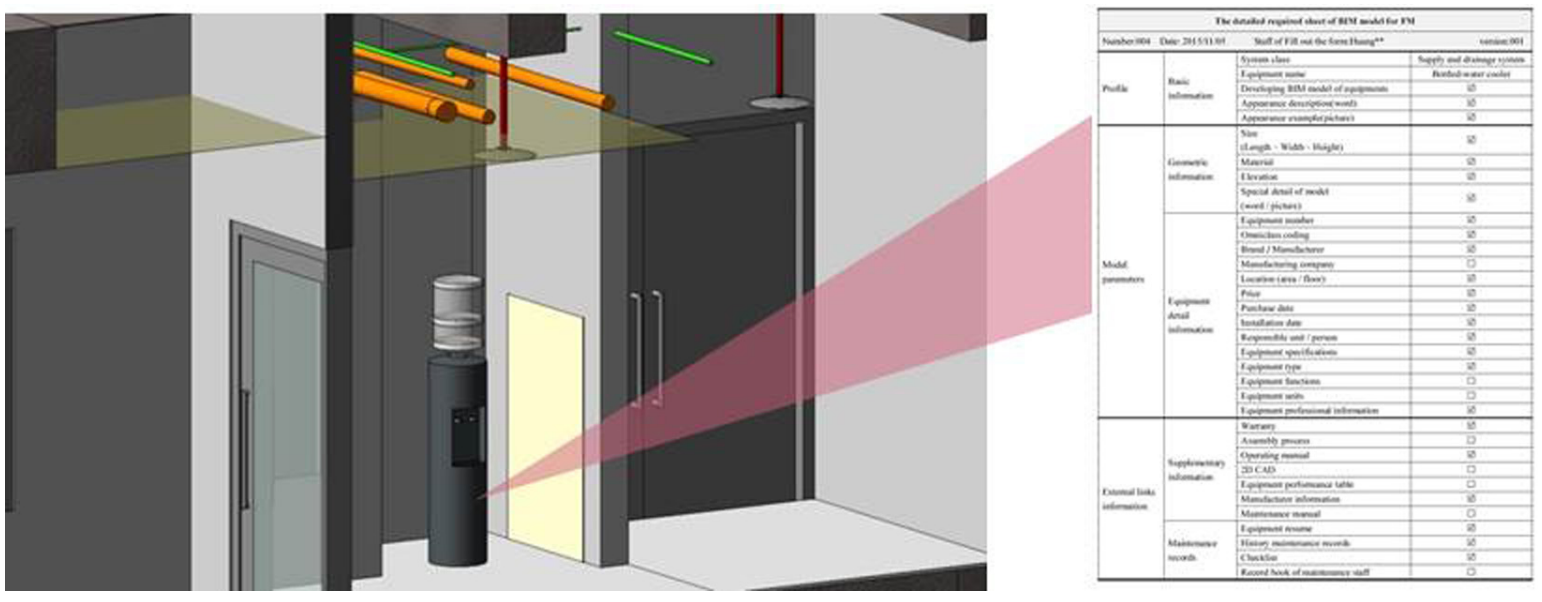

Figure 5. Updated As-Built BIM model of bottled water cooler used in the case study. 


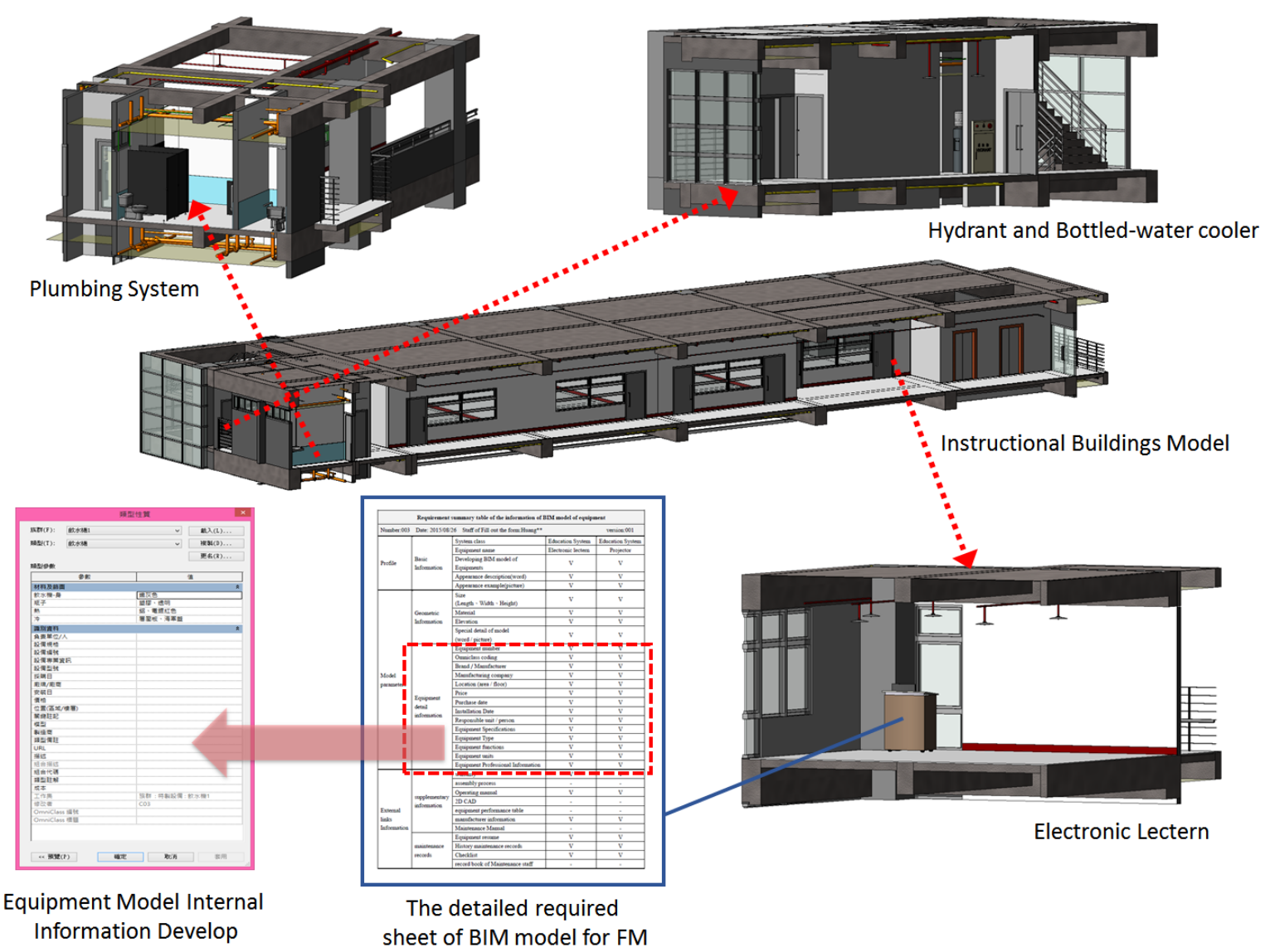

Figure 6. The use of detailed required sheet of BIM model for FM used in the case study.

The following recommendations are based on feedback from the case study: (1) successful BIM implementation adoption should be supported by top management of the owner; (2) processes and strategy must be developed to encourage maturation of the BIM execution plan during the early stages of the operation phase; (3) further effort is required to train FM staff using BIM software to handle revised and updated BIM as-built models; (4) further effort and additional approaches are required to overcome reluctance to adopt BIM technology for FM during the early stages of the operation phase; (5) senior FM staff should be trained to use the as-built models, as many could not use them without assistance; (6) initial case study results should be used to educate users about BIM software adoption; and (7) staff should receive additional training, as required.

The proposed BIM execution plan provided processes for participator of BIM-FM related problems and supported all changes during operation (Figure 7). The principal advantages of the proposed BIM execution plan, based on questionnaire results, are as follows: (1) the FM staff and BIM engineers were able to identify and develop processes for BIM management based on their specific requirements; (2) the FM staff were able to provide guidance on detailed integrated management work of BIM and FM through the proposed documents; (3) the project engineers were able to track the newest versions of as-built models and briefly view changes when using them; and (4) the proposed BIM execution plan enhanced version and change management of as-built models easily and effectively in the web environment. 


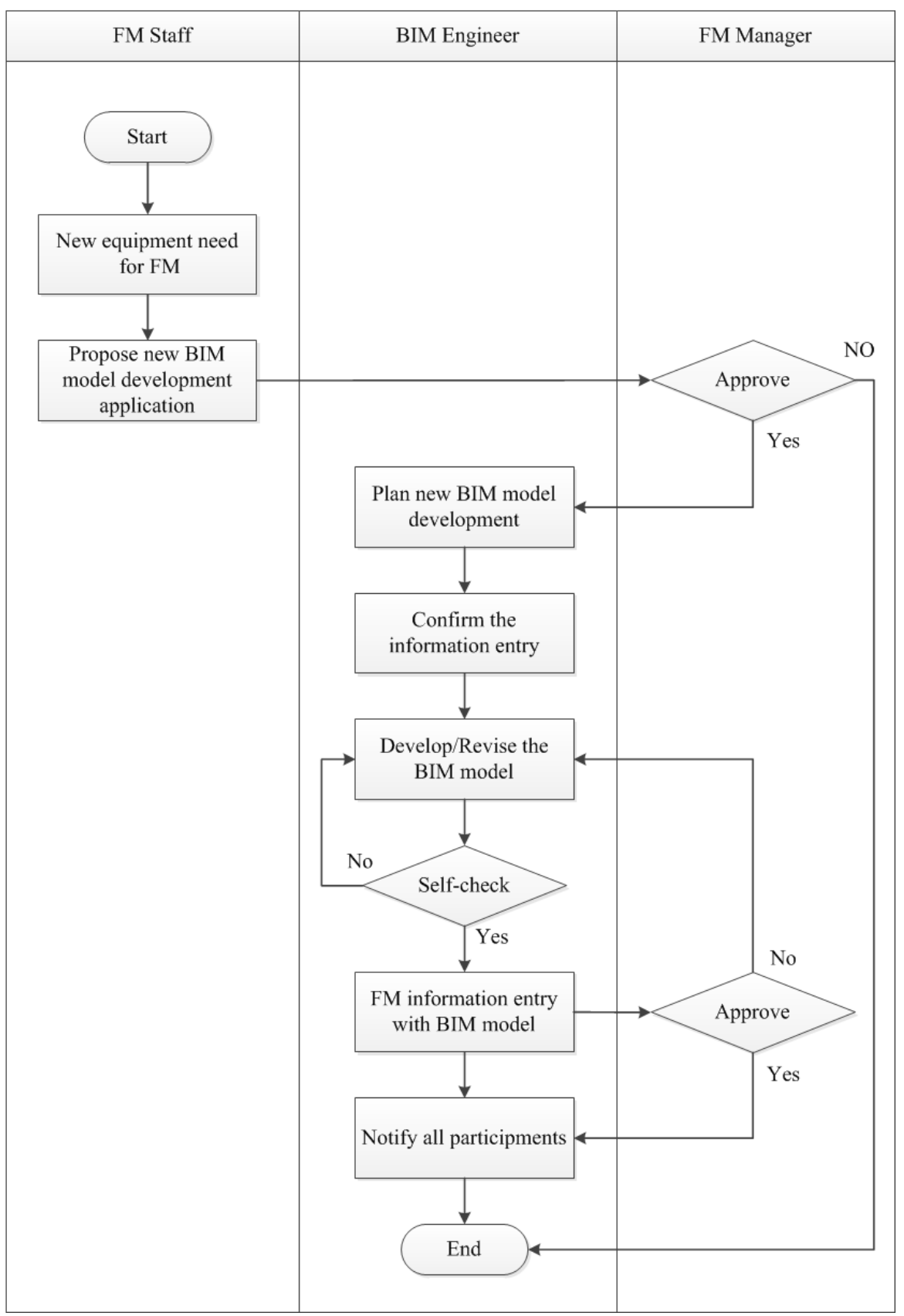

Figure 7. The use of new BIM models inspection process in the case study.

\section{Limitations and Barriers}

The findings of this case study revealed several limitations of the proposed BIM execution plan. The following are inherent problems recognized during the case study.

(1) Although there was good development of the BIM execution plan in the case study, there were nonetheless issues regarding the large number of differences between the as-built BIM models and as-built BIM model for FM. This is a serious problem for BIM-FM implementation in practice. Much time and skilled personnel are required to revise and update the BIM models based on practical BIM-FM requirements.

(2) In the case study, the development of the proposed BIM execution plan initially lengthened the project schedule by two months, After the BIM execution plan was developed, it was difficult for the owner to develop and revise BIM models for two main reasons. Firstly, some FM staff was 
unfamiliar with BIM skills at the early stages of the operation phase and BIM model maintenance (such as BIM model development and revision). FM staff lacked the skills and time to confirm the accuracy of as-built BIM models and revise the errors in the BIM model for FM use. Secondly, many of the required processes were too time-consuming requiring FM staff time to check and confirm the accuracy of as-built BIM models delivered from the general contractor after the close out of the project. FM staff also needed to find the corresponding BIM model and complete the relevant FM-related information. Furthermore, BIM model management work was not the full-time job of FM staff. Therefore, the job of developing new BIM models and revising incorrect BIM models was too time-consuming for FM staff during the initial operation phase.

(3) In the case study, FM staff needed to update BIM models during the initial operation phase with the assistance of and regular communication with BIM engineers as FM staff lacked the skills required for BIM model development. When new equipment or facilities are purchased, FM staff needs to develop new BIM elements regarding to new equipment or facilities for future management use. Furthermore, BIM models require constant maintenance to keep them updated. Therefore, BIM engineers must work together with FM staff to revise and update BIM models during the initial operation phase. The BIM engineers must also notify and discuss with FM staff when the problems of BIM model have been solved or updated.

(4) Another important issue is quality management of BIM models. The study proposed a BIM execution plan to help FM staff handle visual facilities maintenance and management work. However, the advanced management procedures and mechanisms for quality management of BIM models for FM must be identified and developed in the future. Particularly, management mechanisms for BIM models management should be developed in future BIM quality management research.

(5) One of the most challenging tasks with implementing BIM execution plan is the involvement of the BIM engineer in the project. In Taiwan, most of the organizations plan to adopt the BIM execution plan for the use of BIM for FM. However, many organizations need the FM staff that is familiar with BIM skills. While organizations may have a high willingness to implement the BIM execution plan, it is very difficult when these organizations lack the skilled BIM engineer or managers. There are many organizations outsourcing BIM work for FM. Based on Taiwan experience, those organizations that employ the FM staff who are familiar with BIM technology can improve the implementation success rate.

(6) It is potentially challenging for FM staff to adopt the BIM technology as the assistance for the visual FM tool. Based on the case study, some of the FM staff was reluctant in using BIM during the BIM implementation, since they thought their own work would increase because of their direct involvement.

\section{Conclusions}

Building information modeling has changed how FM is implemented during the operation phase. Implementation of FM using visual communication and sharing among different participants has become possible with BIM technology. With the assistance of BIM technology during the operation phase, the performance of facility management integrated with BIM technology should be enhanced for the owner. In order to allow BIM to be used effectively in the operation phase, it is necessary for owners to develop suitable BIM execution plans during pre-operation phase. However, most of the research on BIM use for FM focuses on the study of BIM use and applications during the operation phase. This research proposed a BIM execution plan integrated with seven core elements for BIM model management for BIM-FM integration in the early stages of the operation phase after project closeout. The seven core elements include development of BIM-FM implementation team, development of BIM-FM strategy, development of BIM-FM document, development of BIM-FM process, development of BIM-FM information collection, development of BIM models inspection mechanism, and rules development for BIM models usage for FM. With the proposed BIM-FM implementation team and 
strategy, the BIM execution plan and framework can be implemented effectively. With the assistance of proposed BIM-FM document, process, and information collection, the management of BIM work for FM can be implemented efficiently. Furthermore, the quality of BIM management can be enhanced integrated with the proposed BIM models inspection mechanism and rules development for BIM models usage. Finally, the proposed BIM execution plan was then applied in a selected case study of a building project in Taiwan to verify the proposed methodology and demonstrate its effectiveness in practice. The combined results demonstrated that the proposed BIM execution plan is an effective management approach for operation and maintenance management. The advantages of the proposed BIM execution plan lie not only in how maintenance management work becomes more efficient by integration with BIM technologies, but also in how the value and benefits of BIM are maximized to support maintenance management. Finally, the limitations, difficulties, and suggestions were summarized for further development of the BIM execution plan in practice.

The benefits of implementing the BIM execution plan for BIM model management during the pre-operation phase include:

(1) To follow and handle BIM model management effectively.

(2) To develop the related SOPs of BIM model management effectively.

(3) To easily identify the mistakes and problems that interferes with meeting the requirements of BIM model.

(4) To prepare the initial BIM-related work for FM effectively during the pre-operation phase.

(5) To enhance the successful implementation of BIM for FM.

The major contributions of this research include:

(1) This study proposed a BIM execution plan that provides implementation guidance for BIM model management during the pre-operation phase.

(2) This study discussed the plan and technology requirements establishing the need for industry. It also outlines the technology requirements for BIM model management in the future.

(3) The limitations, challenges, and suggestions are summarized for further development of BIM execution plan based on the case study.

Every BIM use for FM project is unique with different strengths, weaknesses, and priorities. Therefore, it is important to remember that any BIM execution plan for BIM requires different and significant effort for implementation. The procedures proposed in the study can be customized to meet each FM project needs, goals, and mission. While it is recommended to develop standard BIM model management requirements, it was found that all projects cannot be treated the same. The benefits of using BIM operating in an office building are very different from those for a factory. BIM process requirements and developments are a good start for effective implementation, but each project must be individually evaluated. As the BIM execution plan was applied during the pre-operation phase, the BIM execution plan would need to be re-evaluated, and updated.

While this BIM execution plan primarily focuses on owner needs, many of the principals and procedures can be applied to benefit design firms and general contractors. Before the pre-operation phase, it is important and necessary to consider an Industry Foundation Classes (IFC) or COBie format for BIM data's transformation earlier to avoid missing data during the process. Future research will focus on strategic planning during the operation for continuing BIM model development, and further exploration of BIM management and strategies for FM.

Acknowledgments: The authors would like to acknowledge the National Science Council, Taiwan, for financially supporting this work under contract number NSC-103-2221-E-027-036-MY3, and express their appreciation to the all experts' interviews for providing useful data, valuable information, and helpful comments during research development. 
Author Contributions: Yen-Pei Chen, Wan-Ting Huang and Chia-Chun Hong were responsible for the information collection and practical problems analysis; Yen-Pei Chen and Wan-Ting Huang contributed to this paper by developing the methodology and analyzing a case study; Yu-Cheng Lin guided the overall structure and content of the paper; Yu-Cheng Lin, Yen-Pei Chen and Wan-Ting Huang contributed equally to writing of the paper.

Conflicts of Interest: The authors declare no conflict of interest.

\section{References}

1. Lin, Y.C. The Challenge of Application of FM Using BIM Technologies in Taiwan; The BIM Research Report: Taipei, Taiwan, 2012.

2. Eastman, C.; Teicholz, P.; Sacks, R.; Liston, K. BIM Handbook: A Guide to Building Information Modeling for Owners, Managers, Designers, Engineers and Contractors; John Wiley \& Sons: Hoboken, NJ, USA, 2008.

3. Liu, R.; Issa, R. Survey: Common knowledge in BIM for facility maintenance. J. Perform. Constr. Facil. 2015. [CrossRef]

4. William East, E.; Nisbet, N.; Liebich, T. Facility management handover model view. J. Comput. Civ. Eng. 2013, 27, 61-67. [CrossRef]

5. Becerik-Gerber, B.; Jazizadeh, F.; Li, N.; Calis, G. Application areas and data requirements for BIM-enabled facilities management. J. Constr. Eng. Manag. 2012, 138, 431-442. [CrossRef]

6. Wang, Y.; Wang, X.; Wang, J.; Yung, P.; Jun, G. Engagement of facilities management in design stage through BIM: Framework and a case study. Adv. Civ. Eng. 2013, 2013. [CrossRef]

7. Bosch, A.; Volker, L.; Koutamanis, A. BIM in the operations stage: Bottlenecks and implications for owners. Built Environ. Proj. Asset Manag. 2015, 5, 331-343.

8. Kassem, M.; Kelly, G.; Dawood, N.; Serginson, M.; Lockley, S. BIM in facilities management applications: A case study of a large university complex. Built Environ. Proj. Asset Manag. 2015, 5, 261-277.

9. Arayici, Y.; Onyenobi, T.C.; Egbu, C.O. Building information modelling (BIM) for facilities management (FM): The MediaCity case study approach. Int. J. 3D Inf. Model. 2012, 1, 55-73. [CrossRef]

10. Motamedi, A.; Hammad, A.; Asen, Y. Knowledge-assisted BIM-based visual analytics for failure root cause detection in facilities management. Autom. Constr. 2014, 43, 73-83. [CrossRef]

11. Kang, T.W.; Hong, C.H. A study on software architecture for effective BIM/GIS-based facility management data integration. Autom. Constr. 2015, 54, 25-38. [CrossRef]

12. Lin, Y.C.; Su, Y.C.; Chen, Y.P. Developing mobile BIM/2D barcode-based automated facility management system. Sci. World J. 2014, 2014. [CrossRef] [PubMed]

13. Motawa, I.; Almarshad, A. Case-based reasoning and BIM systems for asset management. Built Environ. Proj. Asset Manag. 2015, 5, 233-247.

14. Love, P.; Zhou, J.; Matthews, J.; Chun, P.S.; Carey, B. A systems information model for managing electrical, control, and instrumentation assets. Built Environ. Proj. Asset Manag. 2015, 5, 278-289.

15. Chunduri, S.; Kreider, R.; Messner, J. A case study implementation of the BIM planning procedures for facility owners. AEI 2013, 2013, 691-701.

16. Messner, J.; Kreider, R. BIM Planning Guide for Facility Owners, 2nd ed.; The Computer Integrated Construction Research Program: University Park, PA, USA; Available online: http://bim.psu.edu/ (accessed on 9 October 2014).

(C) 2016 by the authors; licensee MDPI, Basel, Switzerland. This article is an open access article distributed under the terms and conditions of the Creative Commons by Attribution (CC-BY) license (http://creativecommons.org/licenses/by/4.0/). 